\title{
SISTEM PAKAR DIAGNOSA PENYAKIT HIPERTENSI MENGGUNAKAN METODE NAIVE BAYES PADA RSUD ALOE SABOE KOTA GORONTALO
}

\author{
Misrawati Aprilyana Puspa \\ misrawaty@stmik-ichsan.ac.id \\ STMIK Ichsan Gorontalo
}

\begin{abstract}
Abstrak
Hipertensi adalah suatu gangguan pada pembuluh darah yang mengakibatkan suplai oksigen dan nutrisi yang dibawa oleh darah terhambat sampai ke jaringan tubuh yang membutuhkan. Hipertensi sering kali disebut sebagai pembunuh gelap (Silent Killer), karena termasuk penyakit yang mematikan tanpa disertai dengan gejalanya sebagai peringatan bagi korbannya. Penderita hipertensi berkisar dari umur 40 tahun keatas sampai dengan seumur hidup. Pada umumnya Hipertensi disebakan karena faktor keturunan, gaya hidup tidak sehat, mengkonsumsi garam berlebihan, minuman beralkohol serta stres. Sistem pakar bisa menjadi solusi untuk memecahkan masalah karena sistem ini bekerja layaknya seperti pakar dan dirancang menggunakan metode naive bayes dengan melihat rule dan basis aturan yang ada pada penyakit hipertensi. Melalui aplikasi ini, pengguna dapat melakukan konsultasi dengan sistem layaknya berkonsultasi dengan seorang pakar untuk mendiagnosa gejala yang terjadi pada pengguna serta menemukan solusi atas permasalahan yang dihadapi.
\end{abstract}

Kata kunci: Sistem Pakar, Hipertensi, Naive Bayes

\section{Abstract}

Hipertention is desease that happen to arteries that caused the supply of oxygen and nutrition that need by the body blocked. Hipertention often call as a silent killer, because it kind of disease that very harmful but come without awareness to it's victim. People with hipertention in average is up to 40 years old and it happened all of his after life. In common hipertention caused by heredity, unhealthy lifestyle, and trigger by the more salty consumption, alcohol and stress. Expert system could be the solution to solve the problem because this system is worked just like an expert and created by naïve bayes method with the rule and basic system that same just like the hipertantiondesease. Through this application, user can do consultation with this system just like usually people consultation with the expert to diagnostic the sign that happen to user and find the solution of what happened to themselves.

Keywords : Expert System, Hypertention, Naive Bayes

\section{Pendahuluan}

Tekanan darah tinggi, disebut juga hipertensi, merupakan kondisi medis di mana tekanan darah terhadap dinding arteri cukup tinggi sehingga pada akhirnya dapat menyebabkan masalah kesehatan, seperti penyakit jantung. Hal ini disebabkan karena jantung harus bekerja lebih keras dari biasanya untuk mengedarkan darah melalui pembuluh darah ke seluruh tubuh. Tekanan darah umumnya diukur dengan alat yang disebut sphygmomanometer yang terdiri dari sebuah pompa, sebuah pengukur tekanan, dan sebuah manset dari karet. Alat ini mengukur tekanan darah dalam unit yang disebut milimeter air raksa $(\mathrm{mm} \mathrm{Hg})$. Mendiagnosis Tekanan darah tinggi bukan hal yang mudah dikarenakan keterbatasan alat dan hanya beberapa pakar saja yang dapat menangani penyakit ini. Hipertensi adalah suatu gangguan pada pembuluh darah yang mengakibatkan suplai oksigen dan nutrisi yang dibawa oleh darah terhambat sampai ke jaringan tubuh yang membutuhkan. Riwayat penyakit hipertensi yang bersamaan dengan pola hidup tidak sehat seperti mengkonsumsi tembakau, konsumsi tinggi lemak,kurang serat, konsumsi garam berlebih, kurang olah raga, alkoholis, obesitas, lemak darah tinggi dan stres, akan memperberat resiko komplikasi seperti, mengakibatkan infark miokardium, stroke, dan gagal ginjal [1].

Di Indonesia hipertensi merupakan penyebab kematian nomor 3 setelah stroke dan tuberkulosis, yakni $6,7 \%$ dari populasi kematian pada semua umur. Di Indonesia masalah hipertensi cenderung meningkat. Prevalensi di perkotaan 39,9\% (37,0\% - 45,8\%) dan di pedesaan $44,1(36,2 \%-$ 51,7\%) [2]. Menurut Joint National Committe on Prevention Detection, Evaluation, and Treatment of High Blood Pressure VII/ JNC 2003 hipertensi adalah suatu keadaan dimana tekanan darah sistolik $\geq 140 \mathrm{mmHg}$ dan tekanan diastolik $\geq 90 \mathrm{mmHg}$ [3]. 
Dalam mendiagnosa suatu penyakit pada bidang kedokteran dibutuhkan alat bantu seperti aplikasi kecerdasan buatan, oleh karena itu dibuatlah sebuah sistem pakar untuk mendiagnosis penyakit Hipertensi. Dengan adanya sistem pakar ini dapat memudahkan masyarakat dalam mendiagnosa penyakit Hipertensi karena Hipertensi merupakan penyakit yang mematikan tanpa disertai dengan gejala-gejalanya lebih dahulu sebagai peringatan bagi korbannya. Penelitian ini bertujuan Untuk mendapatkan model aplikasi sistem sistem pakar yang menggunakan naive bayes dalam mendiagnosa gejala-gejala penyakit hipertensi yang dapat dilakukan oleh masyarakat. Pada umumnya penelitian ini ditujukan untuk mendapatkan solusi dari hasil berupa konsultasi, diagnosa, dan prediksi. Seperti halnya pada dunia kedokteran, konsultasi, diagnosis dan prediksi sangat diandalkan karena hasilnya dapat mengantisipasi dan mengetahui jenis penyakit yang diderita dengan tepat, cepat dan akurat..

Naïve Bayes merupakan pengklasifikasi probabilitas sederhana berdasarkan pada teorema Bayes. Metode ini digunakan agar pengguna dapat berkomunikasi dengan sistem pakar yang akan dirancang sehingga dapat mempermudah pengguna didalam menggunakan sistem pakar yang dibuat. Sistem pakar pada umumnya merupakan sistem yang berusaha mengadopsi pengetahuan manusia ke komputer, agar komputer dapat menyelesaikan masalah seperti yang biasa dilakukan oleh para ahli atau dengan kata lain sistem pakar adalah sistem yang didesain dan dimplementasikan dengan bantuan bahasa pemrograman tertentu untuk dapat menyelesaikan seperti yang dilakukan oleh para ahli. Sistem pakar bisa menjadi solusi untuk memecahkan masalah karena sistem ini bekerja layaknya seperti pakar dan dirancang menggunakan metode naive bayes dengan melihat rule dan basis aturan yang ada pada penyakit hipertensi [4] .

Melalui aplikasi ini, pengguna dapat melakukan konsultasi dengan sistem layaknya berkonsultasi dengan seorang pakar untuk mendiagnosa gejala yang terjadi pada pengguna serta menemukan solusi atas permasalahan yang dihadapi. Sistem pakar ini dibuat dengan memberikan pertanyaan yang memerlukan jawaban 'ya' atau 'tidak', sesuai atau tidak ataupun dengan beberapa pilihan jawaban yang bersifat anjuran dari gejala yang terjadi. Untuk itu pada penelitian ini akan dirancang sistem dengan judul "Sistem Pakar Diagnosa Penyakit Hipertensi Menggunakan Metode Naive Bayes Pada RSUD Aloe Saboe Kota Gorontalo".

\section{Metode}

\subsection{Sistem Pakar}

Sistem pakar adalah aplikasi berbasis komputer yang digunakan untuk menyelesaikan masalah sebagaimana yang dipikirkan oleh pakar. Pakar yang dimaksud disini adalah orang yang mempunyai keahlian khusus yang dapat menyelesaikan masalah yang tidak dapat diselesaikan oleh orang awam. Sebagai contoh, dokter adalah seorang pakar yang mampu mendiagnosis penyakit yang diderita pasien serta dapat memberikan penatalaksanaan terhadap penyakit tersebut. Program ini bertindak sebagai seorang konsultan yang cerdas atau penasihat dalam suatu lingkungan keahlian tertentu, sebagai hasil himpunan pengetahuan yang telah dikumpulkan dari beberapa orang pakar [5].

Sistem pakar terdiri dari komponen antarmuka pengguna, komponen basis data sistem pakar (expert system database), komponen fasilitas akuisisi pengetahuan (knowledge acquisition facility), dan komponen mekanisme inferensi (inference mechanism). Keungulan sistem pakar antara lain (1) dengan sistem pakar orang awam dapat bekerja layaknya pakar; (2) bisa melakukan proses secara berulang secara otomatis; (3) menyimpan pengetahuan dan keahlian para pakar; (4) mampu mengambil dan melestarikan keahlian para pakar; (5) mampu beroperasi dalam lingkungan yang berbahaya; (6) memiliki reabilitas; (7) mampu untuk bekerja dengan informasi yang tidak lengkap dan mengandung ketidakpastian; (8) menghemat waktu dalam pengambilan keputusan.

\subsection{Naive Bayes}

Naïve Bayes merupakan pengklasifikasi probabilitas sederhana berdasarkan pada teorema Bayes. Keuntungan dari klasifikasi adalah bahwa ia hanya membutuhkan sejumlah kecil data pelatihan untuk memperkirakan parameter (sarana dan varians dari variabel) yang diperlukan untuk klasifikasi. Karena variabel independen diasumsikan, hanya variasi dari variabel untuk masing-masing kelas harus ditentukan, bukan seluruh matriks kovarians. Dalam prosesnya, Naïve Bayes mengasumsikan bahwa ada atau tidaknya suatu fitur pada suatu kelas tidak berhubungan dengan ada atau tidaknya fitur lain di kelas yang sama [4].

Teorema Bayes Menyatakan :

$$
P(B \mid A)=\frac{P(A \mid B) P(B)}{P(A)}
$$


Dimana :

$P(B \mid A)=$ Peluang $B$ jika diketahui keadaan jenis penyakit $A$

$P(B \mid A)=$ Peluang evidence $A$ jika diketahui hipotesis $B$

$\mathrm{P}(\mathrm{B}) \quad=$ Probabilitas hipotesis $\mathrm{B}$ tanpa memandang evidence apapun

$\mathrm{P}(\mathrm{A}) \quad=$ Peluang evidence penyakit $\mathrm{A}$

Menggunakan teorema Bayes ini, persamaan (1) dapat ditulis sebagai berikut:

$$
V_{M A P}=\operatorname{argmax}_{v j \mathrm{EV}} \frac{P\left(a_{1} a_{2} \ldots a_{n} \mid v_{j}\right) p\left(v_{j}\right)}{P\left(a_{1} a_{2} \ldots a_{n}\right)}
$$

Dimana :

$\mathrm{V}_{\mathrm{MAP}} \quad=$ Probabilitas tertinggi.

$P\left(v_{j}\right) \quad=$ Peluang jenis penyakit ke

$P\left(a_{1} a_{2} \ldots a_{n} \mid v_{j}\right)=$ Peluang atribut-atribut (inputan) jika diketahui keadaan $v_{j}$.

$P\left(a_{1} a_{2} \ldots a_{n}\right)=$ Peluang atribut-atribut (inputan)

Karena nilai $P\left(a_{1} a_{2} \ldots a_{n}\right)$ nilainya konstan untuk semua $v_{j}$ sehingga persamaan ini dapat ditulis :

$$
\mathrm{V}_{\mathrm{MAP}}=\operatorname{argmax} v_{\mathrm{jev}} \mathrm{P}\left(\mathrm{v}_{\mathrm{j}}\left|\mathrm{a}_{1}, \mathrm{a}_{2}, \mathrm{a}_{3}, \ldots \mathrm{a}_{\mathrm{n}}\right| \mathrm{v}_{\mathrm{j}}\right) \mathrm{P}\left(\mathrm{v}_{\mathrm{j}}\right)
$$

Dimana :

$\mathrm{V}_{\mathrm{MAP}} \quad=$ Probabilitas tertinggi.

$P\left(v_{j}\right) \quad=$ Peluang jenis penyakit ke $\mathrm{j}$

$P\left(a_{1} a_{2} \ldots a_{n} \mid v_{j}\right)=$ Peluang atribut-atribut (inputan) jika diketahui keadaan $v_{j}$

Untuk menghitung $P\left(\begin{array}{lll}a_{1} & a_{2} \ldots & a_{n} \mid v_{j}\end{array}\right) P\left(v_{j}\right)$ semakin sulit karena jumlah gejala $P\left(\begin{array}{lll}a_{1} & a_{2} \ldots\end{array}\right.$ $\left.a_{n} \mid v_{j}\right) P\left(v_{j}\right)$ bisa jadi sangat besar. Hal ini disebabkan jumlah gejala tersebut sama dengan jumlah semua kombinasi gejala dikali dengan jumlah kategori yang ada.

Perhitungan Naïve bayes classifier adalah menghitung P(ailvj) dengan rumus :

$$
P\left(a_{i} \mid v_{j}=\frac{n_{c}+m p}{n+m}\right.
$$

Dimana :

$\mathrm{n}_{\mathrm{c}}=$ jumlah record pada data learning yang $\mathrm{v}=\mathrm{vj}$ dan $\mathrm{a}=\mathrm{ai}$

$p=1 /$ banyaknya jenis class / penyakit

$\mathrm{m}=$ jumlah parameter / gejala

$\mathrm{n}=$ jumlah record pada data learning yang $\mathrm{v}=\mathrm{vj} /$ tiap class

\subsection{Hipertensi}

Hipertensi adalah suatu gangguan pada pembuluh darah yang mengakibatkan suplai oksigen dan nutrisi yang dibawa oleh darah terhambat sampai ke jaringan tubuh yang membutuhkanya. Penyakit ini seakan menjadi ancaman karena dengan tiba-tiba seseorang dapat divonis menderita darah tinggi [3].

Tabel 1 Klasifikasi pengukuran tekanan darah

\begin{tabular}{|l|c|c|}
\hline \multicolumn{1}{|c|}{$\begin{array}{c}\text { Klasisfikasi Tekanan } \\
\text { Darah }\end{array}$} & $\begin{array}{c}\text { Tekanan Darah Sistolik } \\
(\mathrm{mmHg})\end{array}$ & $\begin{array}{c}\text { Tekanan Darah Diastolik } \\
(\mathrm{mmHg})\end{array}$ \\
\hline Normal & $<120$ & $<80$ \\
\hline Prehipertensi & $120-139$ & $80-89$ \\
\hline Hipertensi & $\geq 140$ & 90 \\
\hline Hipertensi Stage 1 & $140-159$ & $90-99$ \\
\hline Hipertensi Stage 2 & $\geq 160$ & $\geq 100$ \\
\hline
\end{tabular}

Klasifikasi pengukuran terhadap tekanan darah untuk pasien dewasa (umur $\geq 18$ tahun) berdasarkan rata-rata pengukuran tekanan darah atau lebih pada dua atau lebih kunjungan klinis (Tabel 1). Klasifikasi tekanan darah mencakup 4 kategori, dengan nilai normal pada tekanan darah sistolik (TDS) $<120 \mathrm{mmHg}$ dan tekanan darah diastolik (TDD) $<80 \mathrm{mmHg}$. Pre-hipertensi tidak dianggap sebagai kategori penyakit tetapi mengidentifikasi pasien-pasien yang tekanan darahnya cenderung meningkat ke klasifikasi hipertensi dimasa yang akan datang. Ada dua tingkat (stage) hipertensi, dan semua pasien pada kategori ini harus diterapi obat. Krisis hipertensi merupakan suatu keadaan klinis yang ditandai oleh tekanan darah yang sangat tinggi yang kemungkinan dapat menimbulkan atau telah terjadinya kelainan organ target. Biasanya ditandai oleh tekanan darah $>180 / 120 \mathrm{mmHg}$, dikategorikan sebagai hipertensi emergensi atau hipertensi urgensi. Padahipertensi emergensi tekanan darah meningkat ekstrim disertai dengan kerusakan organ target akut yang bersifat progresif, sehingga tekanan darah harus diturunkan segera (dalam hitungan menit - jam) untuk mencegah kerusakan organ target lebih lanjut [6]. 
Hipertensi yang tidak ditangani dengan baik dibedakan menjadi dua kelompok, yaitu faktor risiko yang tidak dapat diubah dan faktor risiko yang dapat diubah.

1. Faktor resiko yang tidak dapat diubah
a. Umur
b. Jenis Kelamin
c. Keturunan (Genetik)

2. Faktor resiko yang dapat dirubah
a. Kegemukan (obesitas)
b. Merokok
c. Kurang aktivitas fisik
d. Konsumsi garam berlebihan
e. Dislipidemia
f. Konsumsi Alkohol Berlebih
g. Psikososial dan Stress

\section{Hasil Dan Pembahasan}

\subsection{Jenis Penyakit Dan Gejala}

Adapun jenis penyakit dan Gejala-gejala untuk penyakit Hipertensi dapat diliat pada tabel 2.

Tabel 2 Jenis-jenis Penyakit

\begin{tabular}{|c|l|}
\hline \multicolumn{2}{|c|}{ Tabel 2 Jenis-jenis Penyakit } \\
\hline Kode & \multicolumn{1}{|c|}{ Nama Penyakit } \\
\hline P01 & Hipertensi Kronis \\
\hline P03 & Superimposed Pre-Eklampsia \\
\hline P04 & Pre-Eklampsia Ringan \\
\hline P05 & Pre-Eklampsia Berat \\
\hline P06 & Eklampsia \\
\hline P07 & Hipotensi \\
\hline
\end{tabular}

Tabel 3 Gejala Penyakit Hipertensi

\begin{tabular}{|c|c|}
\hline Kode & Gejala \\
\hline G01 & Tekanan darah > 120/80 mmHg \\
\hline G02 & Tekanan darah < 120/80 mmHg \\
\hline G03 & Tekanan darah normal atau sama dengan $120 / 80 \mathrm{mmHg}$ \\
\hline G04 & Usia kehamilan $<20$ minggu \\
\hline G05 & Usia kehamilan > 20 minggu \\
\hline G06 & Proteinuria/tes celup urine \\
\hline G07 & Trombosit $<100.000 \mathrm{~mm} 3$ \\
\hline G08 & Trismus/Gangguan pembukaan mulut \\
\hline G09 & Kelelahan \\
\hline G10 & Pingsan \\
\hline G11 & Depresi \\
\hline G12 & Stres \\
\hline G13 & Kejang \\
\hline G14 & Hasil Proteinuria $2.0 \mathrm{~g} /$ hari atau $>2+$ dispstick \\
\hline G15 & Hasil Proteinuria > 300 mg/hari atau >1+dispstick \\
\hline G16 & Oliguria/gangguan air kemih \\
\hline G17 & Volume air kemih/hari < dari 400 ml/jam \\
\hline G18 & Spasme otot/Ketegangan otot \\
\hline
\end{tabular}


ILKOM Jurnal IImiah Volume 10 Nomor 2 Agustus 2018

\begin{tabular}{|l|l|}
\hline G19 & Sakit kepala \\
\hline $\mathbf{G 2 0}$ & Tekanan darah meningkat $>160 / 110 \mathrm{mmHg}$ \\
\hline $\mathbf{G 2 1}$ & Pertumbuhan janin terhambat \\
\hline $\mathbf{G 2 2}$ & Peningkatan kadar enzim ALT atau AST \\
\hline $\mathbf{G 2 3}$ & LDH/Laktat Dehidrogenase meningkat \\
\hline $\mathbf{G 2 4}$ & Demam \\
\hline $\mathbf{G 2 5}$ & Kaku kuduk \\
\hline $\mathbf{G 2 7}$ & Disorientasi \\
\hline $\mathbf{G 2 8}$ & Gangguan penglihatan \\
\hline $\mathbf{G 2 9}$ & Muntah \\
\hline $\mathbf{G 3 0}$ & Kulit berkonsentrasi \\
\hline $\mathbf{G 3 1}$ & Sakit kepala yang berat \\
\hline $\mathbf{G 3 2}$ & Riwayat hipertensi sebelum kehamilan \\
\hline $\mathbf{G 3 3}$ & Multipara \\
\hline $\mathbf{G 3 4}$ & Riwayat hipertensi menurun dalam keluarga \\
\hline $\mathbf{G 3 5}$ & Proteinuria bersifat persisten \\
\hline $\mathbf{G 3 6}$ & Sakit ulu hati \\
\hline $\mathbf{G 3 7}$ & Trombositopeni \\
\hline $\mathbf{G 3 8}$ & Riwayat epilepsi \\
\hline $\mathbf{G 3 9}$ & Hilang kesadaran \\
\hline G40 & Kaku muka \\
\hline G41 & Kaku leher \\
\hline $\mathbf{G 4 2}$ & Kaku tengkuk \\
\hline $\mathbf{G 4 3}$ & Dinding perut kaku \\
\hline & \\
\hline
\end{tabular}

\subsection{Perhitungan Manual Menggunakan Naive Bayes}

Contoh perhitungan dengan menggunakan klasifikasi Naïve bayes dapat diterapkan pada pasien ke -1 yang mengalami gejala nomor $1,9,31,40$.

Keterangan gejala :

1. Tekanan darah $>120 / 80 \mathrm{mmHg}$

9. Kelelahan

31. Sakit kepala yang berat

40. Kaku muka

\section{Langkah-langkah perhitungannya}

Penyakit hipertensi ke - 5 : Pre- Eklampsia Berat

$\mathrm{n}=1$

$p=1 / 7=0.14285714$

$m=43$

1. $n_{c}=1$

9. $\mathrm{n}_{\mathrm{c}}=0$

31. $\mathrm{n}_{\mathrm{c}}=1$

40. $\mathrm{n}_{\mathrm{c}}=0$

Menghitung nilai $P\left(\mathrm{a}_{\mathrm{i}} \mid \mathrm{v}_{\mathrm{j}}\right)$ dan menghitung nilai $P\left(\mathrm{v}_{\mathrm{j}}\right)$

$$
\begin{aligned}
& P(1 \mid \mathrm{PB})=\frac{1+43 \times 0.14285714}{1+43}=0.14285714 \\
& P(9 \mid \mathrm{PB})=\frac{0+43 \times 0.14285714}{1+43}=0.13961039
\end{aligned}
$$




$$
\begin{aligned}
& P(31 \mid P B)=\frac{1+43 \times 0.14285714}{1+43}=0.14285714 \\
& P(40 \mid P B)=\frac{0+43 \times 0.14285714}{1+43}=0.13961039 \\
& P(P B)=1 / 7=0.14285714
\end{aligned}
$$

\section{Menghitung $P\left(a_{i} \mid v_{j}\right) \times P\left(v_{j}\right)$ untuk tiap v}

$$
\begin{aligned}
& \mathrm{P}(\mathrm{PB})=1 / 7=0.14285714 \\
& =\mathrm{P}(\mathrm{PB}) \times[\mathrm{P}(1 \mid \mathrm{PB}) \times \mathrm{P}(9 \mid \mathrm{PB}) \times \mathrm{P}(31 \mid \mathrm{PB}) \times \mathrm{P}(40 \mid \mathrm{PB})]
\end{aligned}
$$$$
=0.14285714 \times[0.14285714 \times 0.13961039 \times 0.14285714 \times 0.13961039]=5.68252473 \mathrm{e}-5
$$

Pada contoh kasus yang diambil pada penelitian ini adalah penyakit Pre-Eklampsia Berat. Awalnya melihat dari gejala-gejala yang dialami oleh pasien yang mengalami penyakit Pre-Eklampsia Berat. Setelah itu langkah selanjutnya adalah menentukan nilai $\mathrm{n}_{\mathrm{c}}$ (jumlah record pada data ) untuk class penyakit Pre-Eklampsia. Setelah kita mengetahui nilainya langkah selanjutnya adalah menghitung nilai $P\left(a_{i} \mid v_{j}\right)$ dan nilai $P\left(v_{j}\right)$ untuk masing-masing gejala pada penyakit Pre-Eklampsia Berat. Setelah hasilnya didapatkan selanjutnya menghitung nilai $P\left(a_{i} \mid v_{j}\right) \times P\left(v_{j}\right)$ untuk tiap $v$ sesuai dengan persamaan 3 diatas. Hasil yang didapatkan untuk penyakit Pre-Eklampsia berat dengan gejala-gejala nya mendapatkan hasil 5.68252473e-5. Hal ini seharusnya dibandingkan dengan gejalagejala lainnya untuk mengetahui jenis penyakit lain yang diderita oleh pasien.

\subsection{Langkah-Langkah Menjalankan Sistem}

Berikut ini adalah tampilan menu awal yang merupakan tampilan utama:

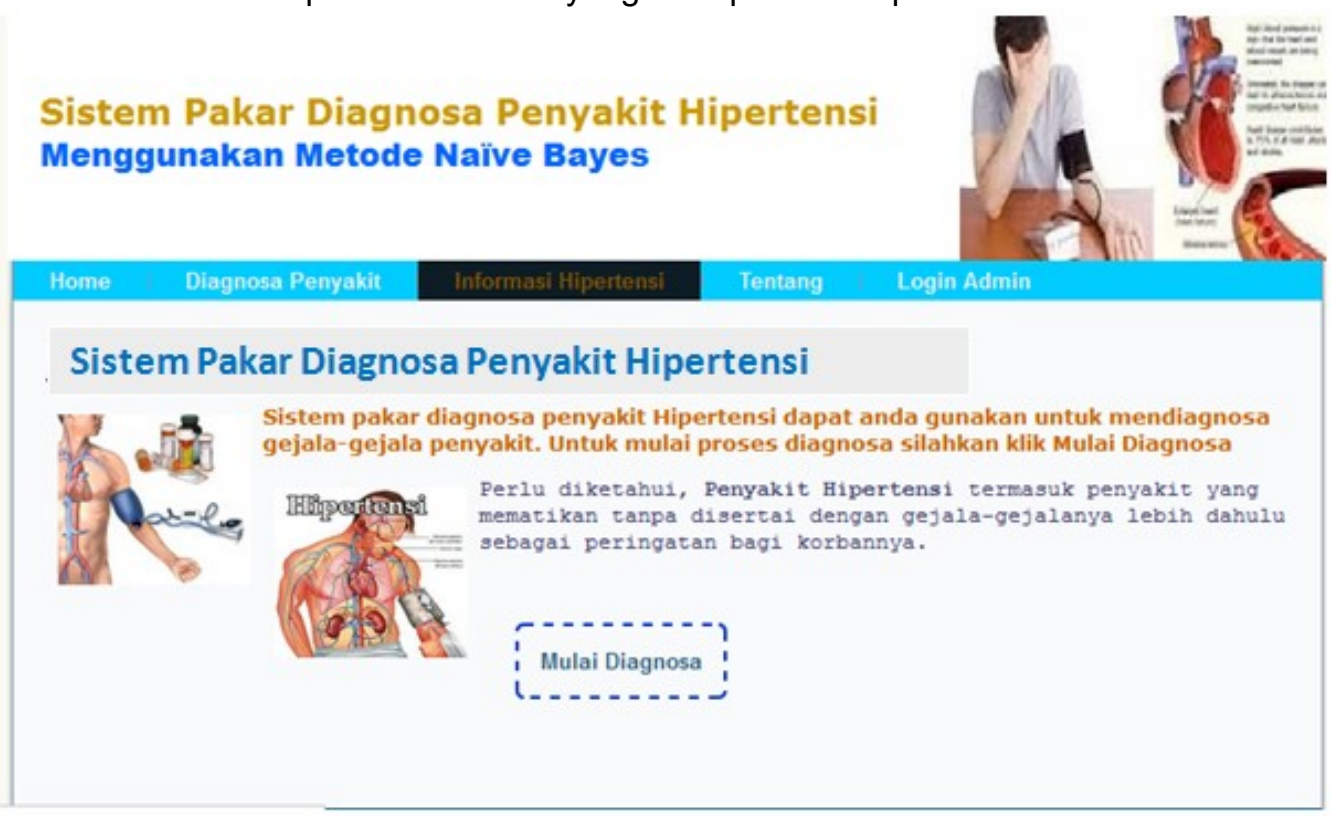

Gambar 1 Tampilan menu utama

Form ini adalah form menu utama dimana pasien dapat memulai untuk mendignosa penyakit hipertensi yang diderita

Halaman Menu Gejala 


\section{Form Konsultasi :}

- $\square$ Tekanan darah $>120 / 80 \mathrm{mmHg}$

- $\square$ Tekanan darah < 120/80 mmHg

- $\square$ Tekanan darah normal atau sama dengan $120 / 80 \mathrm{mmHg}$

- $\square$ Usia kehamilan < 20 minggu

- $\square$ Usia kehamilan > 20 minggu

- $\square$ Proteinuria/tes celup urine

- $\square$ Trismus/Gangguan pembukaan mulut

- $\square$ Kelelahan

- $\square$ Pingsan

- $\square$ Depresi

- $\square$ Kejang

- $\square$ Hasil Proteinuria $2.0 \mathrm{~g} / \mathrm{hari}$ atau $>2+$ dispstick

- $\square$ Hasil Proteinuria $>300 \mathrm{mg} / \mathrm{hari}$ atau $>1+$ dispstick

- $\square$ Volume air kemih/hari < dari $400 \mathrm{ml} / \mathrm{jam}$

- $\square$ Spasme otot/Ketegangan otot

- $\square$ Trombosit < $100.000 \mathrm{~mm} 3$

- $\square$ Stres

- $\square$ Oliguria/gangguan air kemih

- $\square$ Sakit kepala

- $\square$ Tekanan darah meningkat > $160 / 110 \mathrm{mmHg}$

- $\square$ Pertumbuhan janin terhambat

Gambar 2 Tampilan Menu Gejala

Form ini digunakan pasien untuk memilih gejala sesuai yang dialami oleh pasien agar diketahui penyakit hipertensi yang di derita oleh pasien.

\section{Halaman Hasil Diagnosa}

\begin{tabular}{|c|c|}
\hline GEJALA YANG DIALAMI & HASIL DIAGNOSA \\
\hline $\begin{array}{l}\nabla \text { Tekanan darah }>120 / 80 \mathrm{mmHg} \\
\nabla \text { Tekanan darah }<120 / 80 \mathrm{mmHg} \\
\nabla \text { Usia kehamilan }>20 \text { minggu }\end{array}$ & $\begin{array}{l}\text { Berdasarkan hasil diagnosa pada pasien, } \\
\text { Nama : Alan } \\
\text { Jenis Kelamin : Perempuan } \\
\text { Umur : } 27 \\
\text { Alamat : Rambuatan }\end{array}$ \\
\hline & $\begin{array}{l}\text { berdasarkan gejala-gejala yang diinputkan maka dapat } \\
\text { disimpulkan anda mederita penyakit : } \\
\text { Hipertensi Kronis / Sebesar } \mathbf{5 0 \%} \\
\text { Definisi Penyakit : Pada penderita Hipertensi kronis, } \\
\text { terjadi peningkatan tekanan darah pada kehamilan }>24 \\
\text { minggu. Bila disertai dengan proteinuria maka disebut } \\
\text { hipertensi kronis superimposed pre-eklampsia. } \\
\text { Solusi Pengobatan : Checkup sebulan sekali tekanan } \\
\text { darah. hindari minum berakohol, hindari stress berat. }\end{array}$ \\
\hline
\end{tabular}

Gambar 3 Tampilan Hasil Diagnosa

Form ini digunakan untuk melihat hasil diagnosa setelah pasien memasukkan gejala-gejala yang dialami dan diderita oleh pasien.

\subsection{Pengujian Sistem}




\section{Pengujian White Box}

\section{Form Diagnosa}

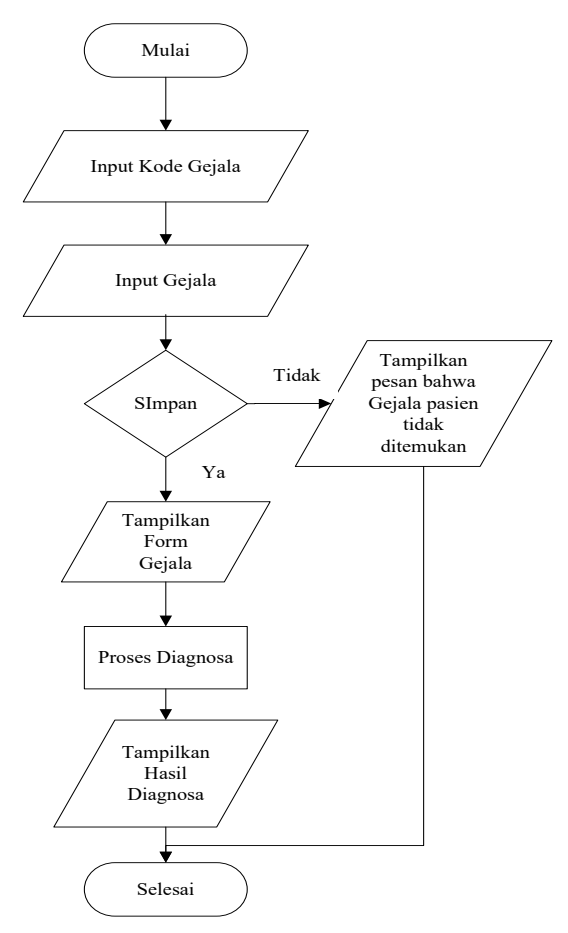

Gambar 7. Flowchart
2. Flowgraph

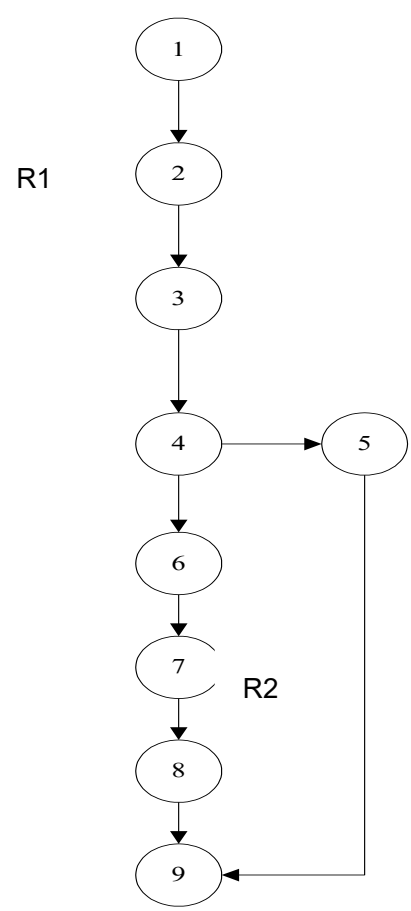

\section{Gambar 8.Flowgraph}

3. Cyclomatic Complexity

Cyclomatic complexity $\mathrm{V}(\mathrm{G})$ untuk grafik alir dihitung dengan rumus :

\section{$\mathbf{V}(\mathbf{G})=\mathrm{E}-\mathrm{N}+\mathbf{2}$}

Dari flowgraph di atas diperoleh :

- $\quad \operatorname{Region}(R)=2$

- $\operatorname{Node}(\mathrm{N})=9$

- Edge $(E) \quad=9$

- $\quad$ Predicate Node $(p)=P+1$
1. $V(G)=E-N+2$$$
=2
$$
2. $V(G)=P+1$

$$
=1+1
$$$$
=2
$$

$=9-9+2$

3. Ciclometic Compexity $(C C)=\mathrm{R} 1, \mathrm{R} 2=2$

Berdasarkan urutan alurnya, didapatkan suatu kelompok basis flow grafh sebagai berikut:

$\mathrm{R} 1=1-2-3-4-6-7-8-9$

$\mathrm{R} 2=1-2-3-4-5-9$

\section{Pengujian Black Box}

Pada pengujian sistem akan dipastikan bahwa suatu event atau masukan akan menjalankan proses yang tepat dan menghasilkan output yang sesuai dengan desain. Untuk pengujian black box diambil form data diagnosa sebagai pengukuran:

Tabel 4. Tabel pengujian black box

\begin{tabular}{|c|c|c|}
\hline Input /Event & Hasil yang diharapkan & $\begin{array}{c}\text { Hasil } \\
\text { Pengujian }\end{array}$ \\
\hline
\end{tabular}


ILKOM Jurnal IImiah Volume 10 Nomor 2 Agustus 2018

\begin{tabular}{|l|l|l|}
\hline Pilih Menu Login & $\begin{array}{l}\text { Menampilkan menu login dengan memasukkan username dan } \\
\text { password kemudian klik login }\end{array}$ & Sukses \\
\hline Pilih menu data pasien & $\begin{array}{l}\text { Menampilkan form yang akan diisi oleh pasien berupa Nama, } \\
\text { Jenis Kelamin, Tanggal Lahir, Alamat dan Nomor Telepon } \\
\text { kemudian klik daftar }\end{array}$ & Sukses \\
\hline Pilih Daftar Gejala & Menampilkan daftar gejala yang diderita oleh pasien & Sukses \\
\hline $\begin{array}{l}\text { Pilih data penyakit dan } \\
\text { solusi }\end{array}$ & $\begin{array}{l}\text { Menampilkan data penyakit dan solusi yang diderita oleh pasien } \\
\text { dengan mengisi kode penyakit, jenis pemeriksaan definisi serta } \\
\text { solusi nya kemudian di simpan }\end{array}$ & Sukses \\
\hline Pilih Diagnosa & $\begin{array}{l}\text { Menampilkan hasil diagnosa yang sesuai dengan gejala-gejala } \\
\text { yang dipilih oleh pasien serta solusi dari penyakit yang dialami. }\end{array}$ & Sukses \\
\hline Pilih exit & Menutup aplikasi & Sukses \\
\hline
\end{tabular}

\section{Kesimpulan Dan Saran}

Dari hasil penelitian di atas maka ditemukan beberapa hal yang dapat disimpulkan bahwa sistem pakar penyakit hipertensi menggunakan metode naive bayes ini dapat membantu masyarakat dalam mendiagnosa penyakit hipertensi. Perhitungan sistem pakar ini dihitung berdasarkan dari proses basis aturan. Setelah melakukan pengujian dari beberapa proses utama yang menggunakan naive bayes, maka secara umum sistem telah bekerja dengan baik. Berdasarkan pada pengujian yang telah dilakukan, penulis memberikan saran yaitu dalam pembuatan sistem selanjutnya dapat menambah dengan fitur-fitur program yang lebih menarik, selain itu diharapkan sistem selanjutnya dapat dikembangkan dengan model perhitungan yang lain, seperti: Fuzzy, GAP, atau yang lainnya dan tentunya mengembangkan ke dalam bentuk aplikasi yang berbasis android sehingga masyarakat akan lebih mudah untuk mengaksesnya.

\section{Daftar Pustaka}

[1] D. Sustrani, Lanny, Preview_ Hipertens, 2004th ed. Jakarta: PT. Gramedia Pustaka Utama.

[2] Setiawan Dalimartha dkk, Buku Care Your self - Hipertensi, 2008th ed. Penebar Plus+, 2008.

[3] Riskesdas, "Badan Penelitian dan Pengembangan Kesehatan Kementerian Kesehatan RI. 2013.," 2013.

[4] Bustami, "Penerapan Algoritma Naive Bayes," J. Inform., vol. 8, no. 1, pp. 884-898, 2014.

[5] Kusrini, Sistem Pakar Teori dan Aplikasi, 2006th ed. Yogyakarta: Penerbit Andi.

[6] A. Muchid, "Pharmaceutical care," Pharm. Care Untuk Pasien penyakit Arthritis Rematik, pp. 53-80, 2006. 